\title{
Diabetes increases the risk of breast cancer: a meta-analysis
}

\author{
Prue J Hardefeldt, Senarath Edirimanne and Guy D Eslick
}

Sydney Medical School Nepean, The Whiteley-Martin Research Centre, Discipline of Surgery, Nepean Hospital, The University of Sydney, Level 5, South Block, PO Box 63, Penrith, New South Wales 2751, Australia

(Correspondence should be addressed to G D Eslick; Email: eslickg@med.usyd.edu.au)

\begin{abstract}
The aim of this meta-analysis was to collate and analyse all primary observational studies investigating the risk of breast cancer $(\mathrm{BC})$ associated with diabetes. In addition, we aimed to complete subgroup analyses by both type of diabetes and gender of study participants to further clarify the origin of any such association between the two. Studies were obtained from a database search of MEDLINE, EMBASE, PubMed, Current Contents Connect and Google Scholar with additional cross-checking of reference lists. Collated data were assessed for heterogeneity and a pooled odds ratio $(\mathrm{OR})$ calculated. Forty-three studies were included in the meta-analysis with 40 studies investigating BC in women and six studies investigating BC in men. Overall, we found a significantly increased risk of BC associated with diabetes in women (OR 1.20, 95\% confidence interval $(\mathrm{Cl})$ 1.13-1.29). After subgroup analysis by type of diabetes, the association was unchanged with type 2 diabetes (OR 1.22, 95\% $\mathrm{Cl} 1.07-1.40$ ) and nullified with gestational diabetes (OR 1.06, 95\% Cl 0.79-1.40). There were insufficient studies to calculate a pooled OR of the risk of $\mathrm{BC}$ associated with type 1 diabetes. There was an increased risk of $\mathrm{BC}$ in males with diabetes mellitus; however, the results did not reach statistical significance (OR 1.29, $95 \% \mathrm{Cl}$ 0.99-1.67). In conclusion, diabetes increases the risk of BC in women. This association is confirmed in women with type 2 diabetes and supports the hypothesis that diabetes is an independent risk factor for $\mathrm{BC}$.
\end{abstract}

Endocrine-Related Cancer (2012) 19 793-803

\section{Introduction}

The increased risk of breast cancer (BC) associated with lifestyle factors has been the subject of numerous observational studies. While there is significant evidence of an increased risk associated with obesity (Harvie et al. 2003), smoking (Khuder et al. 2001, Mucha et al. 2006) and alcohol intake (Key et al. 2006), the risk associated with specific types of diabetes mellitus is yet to be determined. In a metaanalysis published in 2007, Larsson et al. reported an increased risk of $\mathrm{BC}$ associated with non-specific diabetes mellitus; however, due to a lack of primary studies, there was no subgroup analysis by type of diabetes completed.

Liao et al. (2011) published another relevant study in 2011. This meta-analysis focused on studies published after 2000, investigating the association between diabetes and $\mathrm{BC}$ incidence with subgrouping by geographical location and menopausal status.
Interestingly, this study reported an increased BC risk in Europe and America with no increased risk identified in Asia. Furthermore, this study reported a significant association between $\mathrm{BC}$ and diabetes mellitus in only the postmenopausal age group.

In regard to the primary studies, there is a degree of inconsistency in the literature, especially when considering specific types of diabetes. Gestational diabetes has been found to be protective in one study (Rollison et al. 2008) while other studies reported an increased risk (Perrin et al. 2008) or no association between the two (Troisi et al. 1998, Lawlor et al. 2004, Sella et al. 2011). This discrepancy is also present within studies investigating type 2 diabetes mellitus and studies investigating the aetiology of $\mathrm{BC}$ in males.

While the exact mechanism behind any association between diabetes mellitus and $\mathrm{BC}$ has not yet been identified, the main hypothesis at this stage has focused on the hyperinsulinaemia associated with type 2 
diabetes mellitus and consequentially the proliferative effects of insulin. However, it is difficult to isolate diabetes mellitus from potential confounders with other hypotheses focusing on risk factors known to be associated with both diabetes and BC. Obesity is one such example.

The aim of this study was to quantify the risk of BC associated with diabetes. Specifically, we aimed to complete a comprehensive literature search updating the findings of Larsson et al. while also subgrouping the identified studies to investigate the effect of certain types of diabetes on the incidence of $\mathrm{BC}$.

\section{Materials and methods}

\section{Study protocol}

One reviewer $(\mathrm{P} \mathrm{J} \mathrm{H})$, following the meta-analysis of Observational Studies in Epidemiology (MOOSE) guidelines (Stroup et al. 2000), completed a comprehensive database search. The databases, MEDLINE (from 1950), EMBASE (from 1949), PubMed (from 1946), Current Contents Connect (from 1998) and Google Scholar (from 1992), were searched using medical subject headings, text word and key word searches wherever possible. The search terms used were 'diabetes' and 'breast carcinoma' or 'BC' or 'breast neoplasm'. The reference lists of relevant studies were manually checked for missing studies; however, we did not search for unpublished literature.

\section{Study selection}

Studies that met the following inclusion criteria were included in the meta-analysis: i) the risk point estimate was reported as an odds ratio (OR) or the OR could be calculated from the presented data; ii) the $95 \%$ confidence interval (CI) was reported or the CI could be calculated from the presented data; and iii) an internal control group was used to calculate the OR and the internal control group had been diagnosed with neither diabetes nor breast disease. Any study that did not meet the above criteria was excluded from the meta-analysis.

\section{Data extraction}

Data were extracted by a single reviewer $(\mathrm{P} \mathrm{J} \mathrm{H})$ and entered into a standardised data spread sheet (Table 1). For each article, data collected included publication date, study period, study type (cross section (CS), cohort (CO) or case-control (CC)), sample size, mean age, country (geographical and economic status), $\mathrm{OR}, \mathrm{CI}$ and adjusted variables. Where applicable, adjusted ORs were recorded. However, where no OR was given, an unadjusted OR and CI were calculated by the reviewer $(\mathrm{P} \mathrm{J} \mathrm{H})$. Where multiple ORs were given within the same study, i.e. from two different geographical locations, the data were entered as two separate ORs. Studies that did not define the specific type of diabetes were analysed as 'nonspecific diabetes'.

\section{Statistical analysis}

A random effects model was used to calculate a pooled OR for the effect of diabetes on the risk of developing BC. Heterogeneity was assessed using Cochran's Q statistic with a $P$ value of $<0.10$ indicating significant heterogeneity. The extent of heterogeneity was further quantified using the $I^{2}$ statistic with results of 25,50 and $75 \%$ correlating with low, moderate and high levels of heterogeneity respectively. Egger's regression model was used to calculate publication bias with the extent of bias documented using the 'fail safe' method whereby the number of studies required nullifying our results was calculated. A fail safe $(n)$ with a $P$ value $<0.05$ was considered significant. In addition to the Egger's regression model, the Begg and Mazumdar rank correlation was used to assess the symmetrical nature of funnel plot to further assess publication bias. Data were analysed using Comprehensive Meta-analysis (version 2.0).

\section{Results}

The literature search identified 59 studies investigating the association between $\mathrm{BC}$ and diabetes, 16 studies were excluded from the meta-analysis for failing to meet the inclusion criteria (Fig. 1). Eleven studies were excluded for failing to include an internal control group (De Waard \& Baanders Van Halewijn 1974, Ragozzino et al. 1982, Adami et al. 1991, Hjalgrim et al. 1997, Weiderpass et al. 1997, Wideroff et al. 1997, Kath et al. 2000, Zendehel et al. 2003, Swerdlow et al. 2005, Hemminki et al. 2010, Shu et al. 2010), three studies were excluded for investigating mortality rather than incidence (Coughlin et al. 2004, Siegelmann-Danieli et al. 2006, Tseng et al. 2009), one study was excluded for using benign breast disease as a comparator (Muck et al. 1975) and the final study was excluded for investigating the effect of glycaemic control on BC incidence (Stefansdottir et al. 2011). The remaining 43 studies were included in the meta-analysis. 
Table 1 Summary of included studies

\begin{tabular}{|c|c|c|c|c|c|}
\hline Reference & Design & Cases & Controls & $\begin{array}{l}\text { Type of } \\
\text { diabetes }\end{array}$ & Summary of findings \\
\hline Attner et al. (2012) & $\mathrm{CC}$ & 19756 & 147324 & Non-specific & Increased risk of $\mathrm{BC}$ in patients with $\mathrm{DM}$ \\
\hline Baron et al. (2001) & $\mathrm{CC}$ & 5564 & 5841 & Non-specific & $\begin{array}{l}\text { Increased risk of } B C \text { associated with late-onset } D M \text {, } \\
\text { decreased risk of } B C \text { associated with early-onset } D M\end{array}$ \\
\hline Beji \& Reis (2007) & $\mathrm{CC}$ & 405 & 1050 & Non-specific & Increased risk of $\mathrm{BC}$ in patients with DM \\
\hline Bowker et al. (2011) & $\mathrm{CO}$ & 84506 & 84506 & T2DM & No association between $\mathrm{BC}$ and $\mathrm{DM}$ \\
\hline Brinton et al. (2010) & $\mathrm{CO}$ & 111 & 4501578 & Non-specific & Increased risk of $B C$ in patients with DM \\
\hline Carstensen et al. (2012) & $\mathrm{CO}$ & 23846 & 346138 & Non-specific & No association between $\mathrm{BC}$ and $\mathrm{DM}$ \\
\hline Chlebowski et al. (2012) & $\mathrm{CO}$ & 3401 & 64618 & Non-specific & No association between $\mathrm{BC}$ and $\mathrm{DM}$ \\
\hline Chodick et al. (2010) & $\mathrm{CO}$ & 16721 & 83874 & Non-specific & No association between $\mathrm{BC}$ and $\mathrm{DM}$ \\
\hline Cleveland et al. (2012) & $\mathrm{CC}$ & 1447 & 1453 & Non-specific & No significant association between $\mathrm{BC}$ and $\mathrm{DM}$ \\
\hline Ewertz et al. (2001) & $\mathrm{CC}$ & 156 & 468 & Non-specific & Increased risk of $\mathrm{BC}$ in patients with $\mathrm{DM}$ \\
\hline Franceschi et al. (1990) & $\mathrm{CC}$ & 2663 & 2344 & Non-specific & No association between BC and DM \\
\hline Garmendia et al. (2007) & $\mathrm{CC}$ & 170 & 170 & Non-specific & No association between diabetes and $\mathrm{BC}$ \\
\hline Goodman et al. (1997) & $\mathrm{CO}$ & 161 & 22039 & Non-specific & Increased risk of $B C$ in patients with diabetes \\
\hline Hsieh et al. (2012) & $\mathrm{CO}$ & 61777 & 677378 & T2DM & Increased risk of BC associated with T2DM \\
\hline Inoue et al. (2006) & $\mathrm{CO}$ & 4668 & 93103 & Non-specific & No association between $\mathrm{BC}$ and $\mathrm{DM}$ \\
\hline Jee et al. (2005) & $\mathrm{CO}$ & 21056 & 270157 & Non-specific & Increased risk of $B C$ in patients with DM \\
\hline Jordan et al. (2009) & $\mathrm{CC}$ & 43 & 860 & T2DM & Increased risk of $\mathrm{BC}$ in patients with $\mathrm{DM}$ \\
\hline Khachatryan et al. (2011) & $\mathrm{CC}$ & 150 & 152 & T2DM & Increased risk of $\mathrm{BC}$ associated with $\mathrm{T} 2 \mathrm{DM}$ \\
\hline Khan et al. (2006) & $\mathrm{CO}$ & 1554 & 31949 & Non-specific & No association between $\mathrm{BC}$ and DM \\
\hline Lambe et al. (2011) & $\mathrm{CO}$ & 5615 & 218279 & Non-specific & Increased risk of BC in postmenopausal women with DM \\
\hline La Vecchia et al. (1994) & $\mathrm{CC}$ & 9991 & 7834 & Non-specific & No association between $\mathrm{BC}$ and $\mathrm{DM}$ \\
\hline Lawlor et al. (2004) & CS & 147 & 3690 & $\begin{array}{l}\text { Non-specific, } \\
\text { gestational }\end{array}$ & No significant association between $\mathrm{DM}$ and $\mathrm{BC}$ \\
\hline Li et al. (2011) & CS & 48418 & 349365 & Non-specific & Increased risk of $\mathrm{BC}$ associated with $\mathrm{DM}$ \\
\hline Lipscombe et al. (2006) & $\mathrm{CO}$ & 73796 & 391714 & Non-specific & Increased risk of BC associated with DM \\
\hline Michels et al. (2003) & $\mathrm{CO}$ & 6220 & 116488 & T2DM & Increased risk of $\mathrm{BC}$ associated with $\mathrm{T} 2 \mathrm{DM}$ \\
\hline Mink et al. (2002) & $\mathrm{CO}$ & 26 & 7894 & Non-specific & No association between $\mathrm{BC}$ and $\mathrm{DM}$ \\
\hline Moseson et al. (1993) & $\mathrm{CC}$ & 354 & 747 & Non-specific & No significant association between $\mathrm{BC}$ and $\mathrm{DM}$ \\
\hline Perrin et al. (2008) & $\mathrm{CO}$ & 410 & 37516 & Gestational & Increased risk of $\mathrm{BC}$ associated with gestational diabetes \\
\hline Resta et al. (2004) & $\mathrm{CC}$ & 1663 & 4702 & T2DM & Increased risk of $\mathrm{BC}$ associated with T2DM \\
\hline Ronco et al. (2012) & $\mathrm{CC}$ & 367 & 545 & Non-specific & Increased risk of $\mathrm{BC}$ associated with $\mathrm{DM}$ \\
\hline Rollison et al. (2008) & $\mathrm{CC}$ & 2324 & 2523 & $\begin{array}{l}\text { Non-specific, } \\
\text { gestational, } \\
\text { T2DM }\end{array}$ & $\begin{array}{l}\text { Gestational diabetes reduces risk of BC, no association } \\
\text { between T2DM and non-specific DM }\end{array}$ \\
\hline Rosato et al. (2011) & $\mathrm{CC}$ & 3869 & 4082 & Non-specific & Increased risk of $\mathrm{BC}$ associated with $\mathrm{DM}$ \\
\hline Sanderson et al. (2010) & $\mathrm{CC}$ & 190 & 979 & $\begin{array}{l}\text { T2DM, } \\
\text { gestational }\end{array}$ & No association between $\mathrm{DM}$ and $\mathrm{BC}$ \\
\hline Sella et al. (2011) & $\mathrm{CO}$ & 11624 & 174051 & Gestational & No association between gestational diabetes and $\mathrm{BC}$ \\
\hline Sellers et al. (2007) & $\mathrm{CO}$ & 403 & 5727 & T2DM & No significant risk of $\mathrm{BC}$ associated with $\mathrm{DM}$ \\
\hline Sinagra et al. (2002) & CS & 50 & 25 & Non-specific & Increased risk of $\mathrm{BC}$ associated with $\mathrm{DM}$ \\
\hline Steenland et al. (1995) & $\mathrm{CC}$ & 1250 & 11804 & Non-specific & No significant increased risk of $B C$ associated with DM \\
\hline Talamini et al. (1997) & $\mathrm{CC}$ & 2769 & 2588 & Non-specific & Increased risk of BC in postmenopausal women with DM \\
\hline Thomas et al. (1992) & $\mathrm{CC}$ & 227 & 300 & Non-specific & No significant increase in risk of $B C$ in males with $\mathrm{DM}$ \\
\hline Troisi et al. (1998) & $\mathrm{CC}$ & 1239 & 1166 & Gestational & No association between gestational diabetes and BC \\
\hline Weiss et al. (1999) & $\mathrm{CC}$ & 2173 & 1990 & Non-specific & No association between $\mathrm{BC}$ and $\mathrm{DM}$ \\
\hline Wu et al. (2007) & $\mathrm{CC}$ & 1248 & 1148 & T2DM & Increased risk of $\mathrm{BC}$ associated with T2DM \\
\hline Yu et al. (2012) & $\mathrm{CC}$ & 103 & 309 & Non-specific & No significant increased risk of $\mathrm{BC}$ associated with DM \\
\hline
\end{tabular}

\section{Non-specific diabetes mellitus}

Forty studies were identified investigating diabetes and the risk of BC in women. Fourteen studies reported a statistically significant increase in $\mathrm{BC}$ incidence in patients with diabetes mellitus (Goodman et al. 1997, Sinagra et al. 2002, Michels et al. 2003, Resta et al. 2004, Jee et al. 2005, Lipscombe et al. 2006, Beji \&
Reis 2007, Wu et al. 2007, Jordan et al. 2009, Khachatryan et al. 2011, Rosato et al. 2011, Attner et al. 2012, Hsieh et al. 2012, Ronco et al. 2012) while 24 studies reported results that did not reach statistical significance. Within these 24 studies, 17 studies had risk point estimates that favoured an increased risk of BC (Steenland et al. 1995, Talamini et al. 1997, 


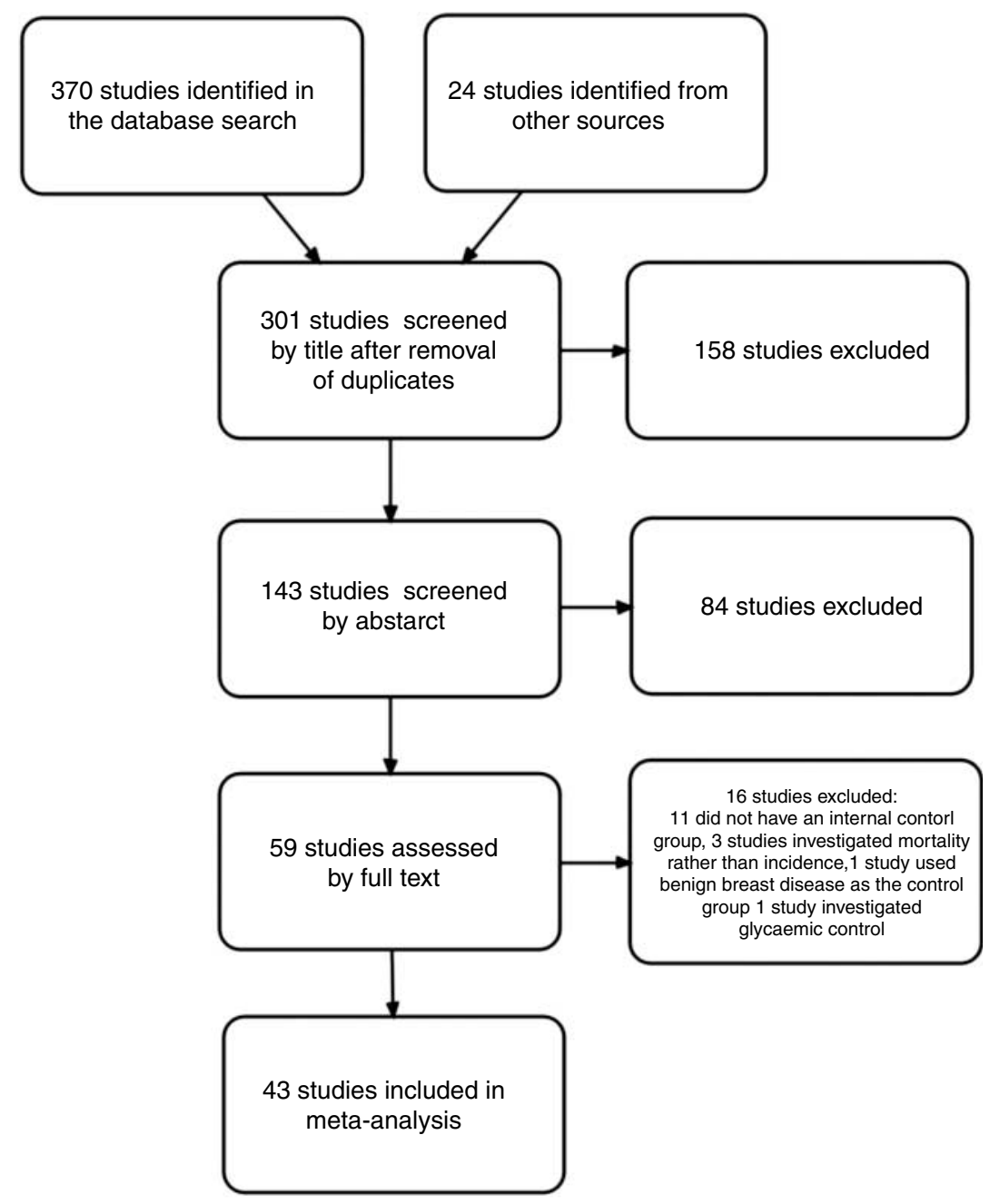

Figure 1 Results of the literature search.

Troisi et al. 1998, Weiss et al. 1999, Baron et al. 2001, Mink et al. 2002, Lawlor et al. 2004, Khan et al. 2006, Garmendia et al. 2007, Sellers et al. 2007, Perrin et al. 2008, Sanderson et al. 2010, Lambe et al. 2011, Li et al. 2011, Carstensen et al. 2012, Cleveland et al. 2012, Yu et al. 2012) while six studies favoured a decreased risk (Moseson et al. 1993, Inoue et al. 2006, Rollison et al. 2008, La Vecchia et al. 1994, Sella et al . 2011, Chlebowski et al. 2012). Three studies found no association between the two (Franceschi et al. 1990, Chodick et al. 2010, Bowker et al. 2011). Quantitative analysis revealed a significant pooled risk point estimate of 1.20 (95\% CI 1.13-1.29) (Fig. 2). Heterogeneity was high $\left(I^{2}=73.41, P<0.001\right)$ and there was evidence of publication bias $(n=932$, Egger's $P=0.01$ ). However, the funnel plot was found to be symmetrical using the Begg and Mazumdar rank correlation $(P=0.07$; Fig. 3$)$.
Subgroup analysis by study design identified a slightly increased risk of $\mathrm{BC}$ in $\mathrm{CC}$ studies when compared with $\mathrm{CO}$ studies evident in risk point estimates of 1.29 (95\% CI 1.12-1.49) and 1.12 (95\% CI 1.05-1.20) respectively. The pooled analysis for cross-sectional studies was not significant despite an increased risk point estimate (OR 1.33, 95\% CI 0.81-2.17).

To investigate the effect of confounders on BC incidence, a subgroup analysis was undertaken investigating only studies that adjusted for known risk factors of BC. Twenty-one studies adjusted for age and BMI with the pooled risk point estimate identifying a statistically significant increase in $\mathrm{BC}$ risk (OR 1.12, 95\% CI 1.04-1.21) with no evidence of heterogeneity $\left(I^{2}=30.78, P=0.09\right)$. In a bid to further demonstrate causality, studies that adjusted for family history in addition to age and BMI were collated with 
Study name

Attner et al. (2012)

Baron et al. (2001)

Beji \& Reis (2007)

Bowker et al. (2011)

Carstensen et al. (2012)

Chlebowski et al. (2012)

Cleveland et al. (2012)

Chodick et al. (2010)

Franceschi et al. (1990)

Garmendia et al. (2007)

Goodman et al. (1997)

Hsieh et al. (2012)

Inoue et al. (2006)

Jee et al. (2005)

Jordan et al. (2009)

Khachatryan et al. (2011)

Khan et al. (2006)

Lambe et al. (2011)

LaVecchia et al. (1994)

Lawler et al. (2004)

Li et al. (2011)

Lipscombe et al. (2006)

Michaels et al. (2003)

Mink et al. (2002)

Moseson et al. (1993)

Perrin et al. (2008)

Resta et al. (2004)

Rollison et al. (2008)

Ronco et al. (2012)

Rosato et al. (2011), Italy

Rosato et al. (2011), Switzerland

Sanderson et al. (2010)

Sella et al. (2011)

Sellers et al. (2007)

Sinagra et al. (2002)

Steenland et al. (1995)

Talamini et al. (1997)

Troisi et al. (1998)

Weiss et al. (1999)

Wu et al. (2007)

Yu et al. (2012)
Statistics for each study

\begin{tabular}{lccc|l} 
Odds & Lower & Upper & Pvalue & \\
ratio & limit & limit & val \\
1.37 & 1.10 & 1.71 & 0.01 & \\
1.10 & 0.93 & 1.30 & 0.26 & \\
3.31 & 2.36 & 4.64 & 0.00 & \\
1.00 & 0.91 & 1.10 & 1.00 & \\
1.05 & 1.02 & 1.08 & 0.00 & \\
0.99 & 0.85 & 1.15 & 0.89 & \\
1.27 & 0.95 & 1.69 & 0.10 & \\
1.00 & 0.84 & 1.19 & 1.00 & \\
1.00 & 0.77 & 1.30 & 1.00 & \\
1.60 & 0.73 & 3.52 & 0.24 & \\
2.06 & 1.27 & 3.34 & 0.00 & \\
1.11 & 1.02 & 1.21 & 0.02 & \\
0.83 & 0.44 & 1.57 & 0.57 & \\
1.51 & 1.26 & 1.80 & 0.00 & \\
8.40 & 1.71 & 41.25 & 0.01 & \\
5.53 & 1.34 & 22.82 & 0.02 & \\
1.55 & 0.62 & 3.86 & 0.35 & \\
1.15 & 0.42 & 3.14 & 0.79 & \\
0.80 & 0.64 & 1.00 & 0.05 & \\
1.42 & 0.80 & 2.52 & 0.23 & \\
1.10 & 0.93 & 1.30 & 0.26 & \\
1.08 & 1.01 & 1.16 & 0.03 & \\
1.17 & 1.01 & 1.35 & 0.03 & \\
1.39 & 0.86 & 2.24 & 0.18 & \\
0.70 & 0.33 & 1.50 & 0.36 & \\
1.50 & 1.07 & 2.10 & 0.02 & \\
1.54 & 1.24 & 1.91 & 0.00 & \\
0.98 & 0.81 & 1.18 & 0.83 & \\
1.60 & 0.95 & 2.69 & 0.08 & \\
1.00 & 0.75 & 1.33 & 1.00 & \\
1.72 & 1.30 & 2.27 & 0.00 & \\
1.02 & 0.71 & 1.47 & 0.92 & \\
0.87 & 0.63 & 1.20 & 0.40 & \\
1.61 & 0.98 & 2.63 & 0.06 & \\
8.43 & 1.03 & 69.18 & 0.05 & \\
1.40 & 0.70 & 2.79 & 0.34 & \\
1.40 & 1.09 & 1.80 & 0.01 & \\
1.10 & 0.81 & 1.50 & 0.55 & \\
1.13 & 0.69 & 1.86 & 0.63 & \\
1.71 & 1.15 & 2.54 & 0.01 & \\
1.58 & 0.77 & 8.63 & 0.12 & \\
& 1.13 & 1.29 & 0.00 & \\
& & & & \\
& & &
\end{tabular}

Odds ratio and $95 \% \mathrm{Cl}$

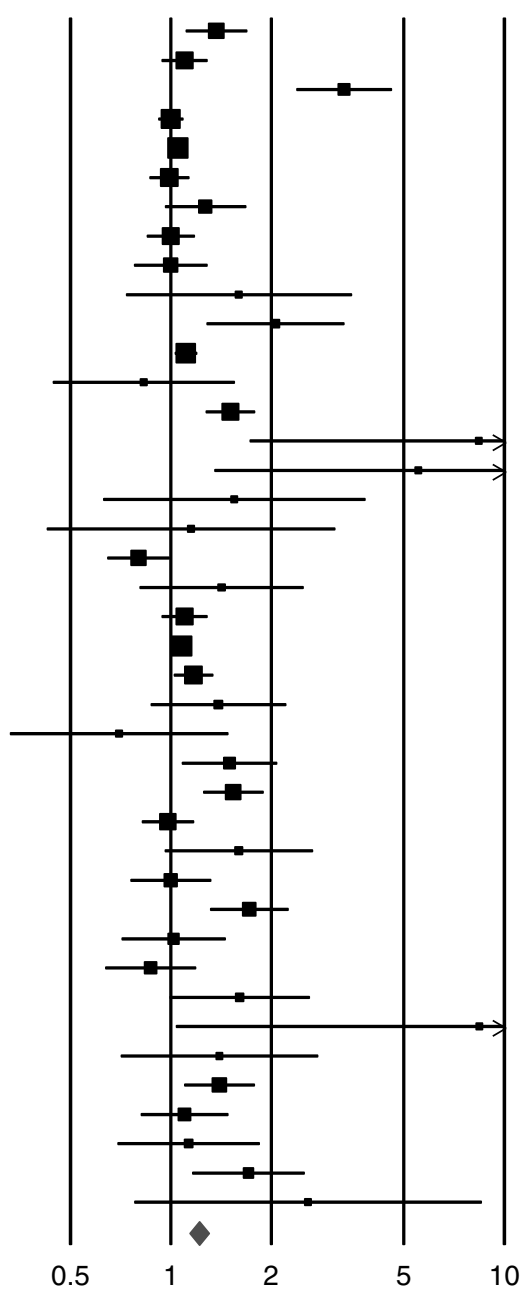

Figure 2 Diabetes and breast cancer incidence in women.

the results continuing to favour an increased risk of $\mathrm{BC}$ in patients with diabetes mellitus (OR 1.11, 95\% CI $\left.1.01-1.22, I^{2}=25.02, P=0.23\right)$.

\section{Male BC}

Seven studies were identified investigating the association between $\mathrm{BC}$ and diabetes mellitus in men (Lenfant-Pejovic et al. 1990, Thomas et al. 1992, Ewertz et al. 2001, Brinton et al. 2010, Chodick et al. 2010, Li et al. 2011, Carstensen et al. 2012). Five studies were homogenous in their finding of an increased risk point estimate; however, only two studies reached statistical significance (Ewertz et al. 2001, Brinton et al. 2010). The remaining two studies, despite not reaching statistical significance, favoured a protective effect associated with diabetes mellitus. The pooled OR favoured an increased risk of $\mathrm{BC}$ in males with diabetes mellitus (OR 1.29, 95\% CI 0.99-1.67) (Fig. 4). There was no evidence of heterogeneity $\left(I^{2}=32.83, P=0.18\right)$.

\section{Type 2 diabetes mellitus}

Subgroup analysis of non-specific diabetes mellitus in women identified ten studies that specifically investigated type 2 diabetes mellitus (Michels et al. 2003, Resta et al. 2004, Sellers et al. 2007, Wu et al. 2007, Rollison et al. 2008, Jordan et al. 2009, Sanderson et al. 2010, Bowker et al. 2011, Khachatryan et al. 2011, Hsieh et al. 2012). Eight studies reported a positive risk point estimate with six studies reaching 
Funnel plot of precision by log odds ratio

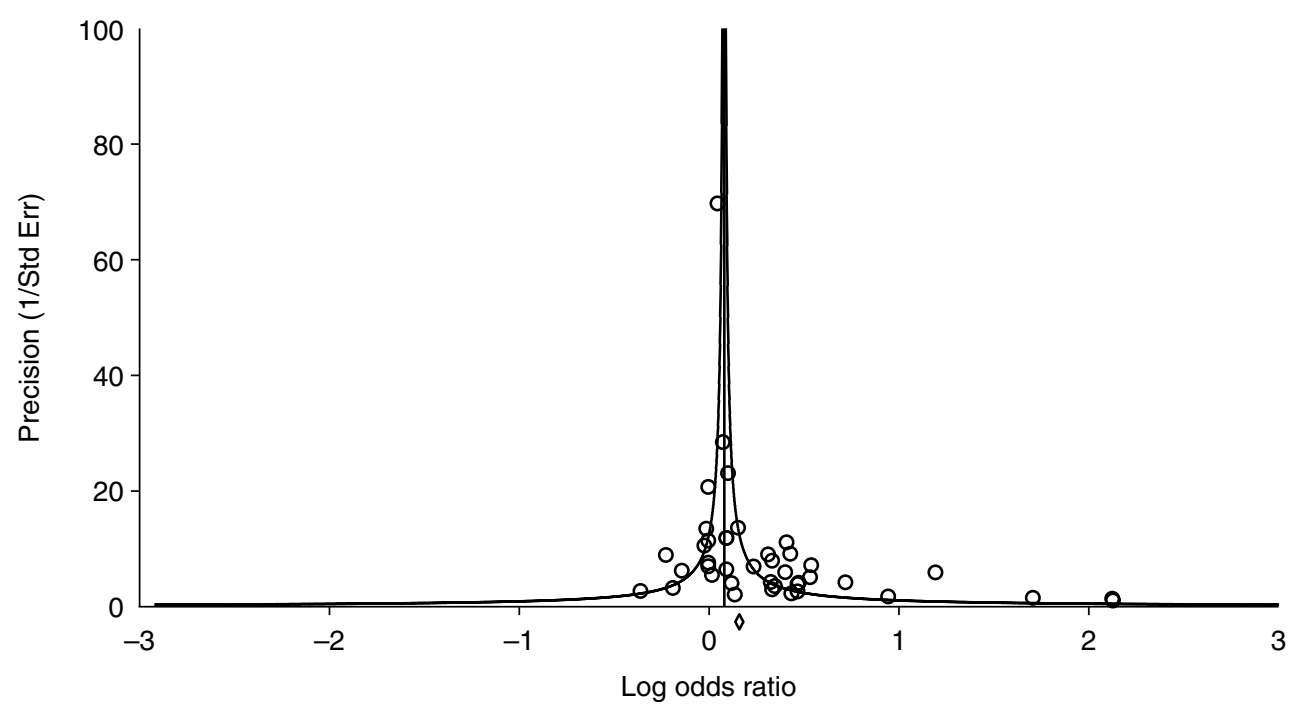

Figure 3 Funnel plot assessing publication bias.

statistical significance (Michels et al. 2003, Resta et al. 2004, Wu et al. 2007, Jordan et al. 2009, Khachatryan et al. 2011, Hsieh et al. 2012). The final two studies did not find any association between the two (Sanderson et al. 2010, Bowker et al. 2011). The pooled OR and $95 \%$ CI supported an increased risk of $\mathrm{BC}$ associated with type 2 diabetes mellitus (OR 1.22, 95\% CI 1.07-1.40) (Fig. 5).

\section{Type 1 diabetes mellitus}

The literature search identified three studies investigating the effect of type 1 diabetes mellitus on $\mathrm{BC}$ incidence. However, all three studies failed to meet the inclusion criteria with two studies failing to include an internal control group (Zendehel et al. 2003, Shu et al. 2010) while one study assumed a diagnosis of type 1 diabetes mellitus in all patients aged under
35 years without confirmation (Baron et al. 2001). Interestingly, the studies were homogenous in their finding of a protective risk point estimate despite none of the studies reaching statistical significance. Quantitative analysis was not undertaken on account of the studies failing to meet the inclusion criteria.

\section{Gestational diabetes}

Six studies were identified investigating the effect of gestational diabetes on $\mathrm{BC}$ incidence (Troisi et al. 1998, Lawlor et al. 2004, Perrin et al. 2008, Rollison et al. 2008, Sella et al. 2011). There was a degree of heterogeneity within the results with only one study reaching statistical significance (Rollison et al. 2008). This study found gestational diabetes to reduce the risk of BC. The remaining four studies did not reach statistical significance with three studies finding an

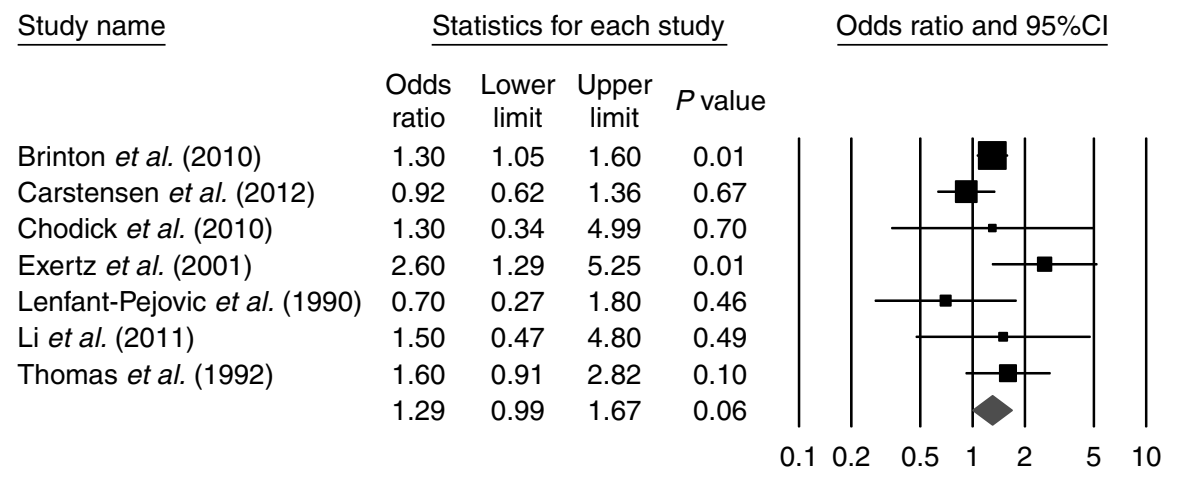

Figure 4 Diabetes and breast cancer incidence in men. 


\begin{tabular}{lccccc} 
Study name & \multicolumn{5}{c}{ Statistics for each study } \\
\cline { 3 - 6 } & & $\begin{array}{c}\text { Odds } \\
\text { ratiol }\end{array}$ & $\begin{array}{c}\text { Lower } \\
\text { limit }\end{array}$ & $\begin{array}{c}\text { Upper } \\
\text { limit }\end{array}$ & $P$ value \\
Bowker et al. (2011) & 1.00 & 0.91 & 1.10 & 1.00 \\
Hsieh et al. (2012) & 1.11 & 1.02 & 1.21 & 0.02 \\
Jordan et al. (2009) & 8.40 & 1.71 & 41.25 & 0.01 \\
Khachatryan et al. (2011) & 5.53 & 1.34 & 22.82 & 0.02 \\
Michaels et al. (2003) & 1.17 & 1.01 & 1.35 & 0.03 \\
Resta et al. (2004) & 1.54 & 1.24 & 1.91 & 0.00 \\
Rollison et al. (2008) & 1.06 & 0.85 & 1.32 & 0.60 \\
Sanderson et al. (2010) & 1.00 & 0.66 & 1.51 & 1.00 \\
Seller et al. (2007) & 1.61 & 0.98 & 2.63 & 0.06 \\
Wu et al. (2007) & 1.71 & 1.15 & 2.54 & 0.01 \\
& 1.22 & 1.07 & 1.40 & 0.00
\end{tabular}

Figure 5 Type 2 diabetes and breast cancer incidence.

increased risk point estimate (Troisi et al. 1998, Lawlor et al. 2004, Perrin et al. 2008) and one study reporting a negative risk point estimate (Sella et al. 2011). The pooled OR did not find any association between gestational diabetes and BC (OR 1.06, 95\% CI $0.79-1.40)$ while significant heterogeneity was present $\left(I^{2}=68.81, P=0.01\right)$.

\section{Discussion}

Our study identified a $20 \%$ increased risk of BC in people with diabetes mellitus. This association was unchanged when considering only people with confirmed type 2 diabetes mellitus while there was no evidence of an increased risk associated with type 1 diabetes mellitus. These findings are consistent with the hyperinsulinaemia hypothesis as a potential mechanism linking diabetes mellitus to BC.

While type 1 diabetes mellitus is predominantly associated with insulin deficiency, type 2 diabetes is more readily known for its hyperinsulinaemic state. This is particularly seen in the early stages of the disease where the pancreas is still able to compensate for the hyperglycaemia. This increase in insulin is hypothesised to increase proliferation in two ways; activation of the insulin receptor substrate to increase mitosis at a cellular level (Chan \& Lee 2008) and causing an imbalance in sex steroids via a decrease in sex hormone binding globulin (Nestler 2000). However, we cannot exclude an indirect relationship with potential confounders triggering a rise in plasma oestrogen. For example, obesity has also been shown to trigger a reduction in sex hormone binding globulin and consequentially an increase in the bioavailability of oestrogen. In addition, adipose tissue is known to generate an increase in plasma oestrogen via the aromatase enzyme, thus providing an alternate mechanism linking diabetes to BC (Ballard-Barbash et al. 1990, Carmichael \& Bates 2004).

Another hypothesis centres on an iatrogenic link between $\mathrm{BC}$ and diabetes mellitus. Insulin use has long been suspected of increasing the risk of $\mathrm{BC}$ and more recently the debate has focused on the use of insulin glargine. Jonasson et al. (2009) in a study published in 2009 found an increased risk of BC associated with glargine use. These results, however, have not been replicated in other observational studies (Colhoun \& Group 2009, Currie et al. 2009, Home \& Lagarenne 2009). Additionally, while there has been a degree of heterogeneity in the results of broader studies investigating insulin use in general (rather than specifically glargine use), a recent Danish study did not find an association between the risk of $\mathrm{BC}$ in people using insulin and people using other antiglycaemic agents (Carstensen et al. 2012).

Metformin use, on the other hand, has actually been shown to reduce the risk of BC (Bodmer et al. 2010). Hypothesised mechanisms explaining this protective effect include metformin's ability to reduce the hyperinsulinaemia associated with type 2 diabetes and in vitro evidence of direct anticarcinogenic properties (Martin-Castillo et al. 2010, Belda-Iniesta et al. 2011). While a number of observational studies have confirmed this protective effect, a recent study specifically identified a $25 \%$ reduction in $\mathrm{BC}$ incidence associated with metformin use (Chlebowski et al. 2012). New evidence has also indicated that metformin use may improve prognosis (Jiralerspong et al. 2009). 
The vast majority of the included studies comprised broad, large-scale observational studies, which took neither current nor past therapeutic regimes into account. For this reason, we were unable to exclude antiglycaemic therapy as a potential confounder. This constraint, in the context of new evidence potentially linking antiglycaemic agents to $\mathrm{BC}$ incidence, is a major limitation in our study. We recommend that all future primary studies take both past and present therapy into account when considering aspects of study design. In addition, the effect of diabetes mellitus on different types of BC has not been thoroughly assessed and it may be worthwhile for future studies to also take this into account.

A further weakness in this study lay in our inability to differentiate between the different types of diabetes investigated. Thirty-four studies were included in this analysis; however, only 13 of these studies specifically stated the type of diabetes investigated. While the vast majority of the studies had a mean age above 50 years, and thus a diagnosis of type 2 diabetes was most likely, we were unable to include the studies in our subgroup analysis. For this reason, the power of the subgroup analysis in type 2 diabetes mellitus was reduced. Furthermore, with only three studies investigating the association between type 1 diabetes mellitus and all three studies failing to meet the inclusion criteria, we were unable to quantitatively analyse the results. For future research, we recommend further longitudinal studies of high quality be undertaken in this area.

Strengths of this study include a broad literature review, the use of precise inclusion criteria and comprehensive subgrouping to identify the differences between types of diabetes. We used five databases as well as reference list checking to identify relevant studies with double the number of studies identified compared with previous reviews (Larsson et al. 2007, Liao et al. 2011). The increased number of studies allowed subgroup analysis by type of diabetes for the first time.

In conclusion, in patients with diabetes mellitus, we have found a $20 \%$ increase in the incidence of BC in women and $29 \%$ increase in men. This association was unchanged when the analysis was restricted to studies with a confirmed diagnosis of type 2 diabetes mellitus. These findings are consistent with the hyperinsulinaemia theory in the aetiology of BC.

\section{Declaration of interest}

The authors declare that there is no conflict of interest that could be perceived as prejudicing the impartiality of the research reported.

\section{Funding}

This research did not receive any specific grant from any funding agency in the public, commercial or not-for-profit sector.

\section{Author contribution statement}

All authors contributed to the conception, design and interpretation of the data; the preparation of the manuscript; and the final editing and approval of the manuscript.

\section{References}

Adami HO, Mc Laughlin J, Ekbom A, Berne C, Silverman D, Hacker D \& Persson I 1991 Cancer risk in patients with diabetes mellitus. Cancer Causes \& Control 2 307-314. (doi:10.1007/BF00051670)

Attner B, Landin-Olsson M, Lithman T, Noreen D \& Olsson H 2012 Cancer among patients with diabetes, obesity and abnormal blood lipids: a population-based register study in Sweden. Cancer Causes \& Control $\mathbf{2 3}$ 769-777. (doi:10.1007/s10552-012-9946-5)

Ballard-Barbash R, Schatzkin A, Taylor PR \& Kahle LL 1990 Association of change in body mass with breast cancer. Cancer Research 50 2152-2155.

Baron JA, Weiderpass E, Newcomb PA, Stampfer M, Titus-Ernstoff L, Egan KM \& Greenberg ER 2001 Metabolic disorders and breast cancer risk (United States). Cancer Causes \& Control 12 875-880. (doi:10.1023/A:1013796112348)

Beji NK \& Reis N 2007 Risk factors for breast cancer in Turkish women: a hospital-based case-control study. European Journal of Cancer Care 16 178-184. (doi:10.1111/j.1365-2354.2006.00711.x)

Belda-Iniesta C, Pernia O \& Simo R 2011 Metformin: a new option in cancer treatment. Clinical and Translational Oncology 13 363-367. (doi:10.1007/s12094-011-0669-y)

Bodmer M, Meier C, Krahenbuhl S, Jick SS \& Meier CR 2010 Long-term metformin use is associated with decreased risk of breast cancer. Diabetes Care $\mathbf{3 3}$ 1304-1308. (doi:10.2337/dc09-1791)

Bowker SL, Richardson K, Marra CA \& Johnson JA 2011 Risk of breast cancer after onset of type 2 diabetes: evidence of detection bias in postmenopausal women. Diabetes Care 34 2542-2544. (doi:10.2337/dc11-1199)

Brinton LA, Carreon JD, Gierach GL, McGlynn KA \& Gridley G 2010 Etiologic factors for male breast cancer in the U.S. Veterans Affairs medical care system database. Breast Cancer Research and Treatment 119 185-192. (doi:10.1007/s10549-009-0379-0)

Carmichael AR \& Bates T 2004 Obesity and breast cancer: a review of the literature. Breast 13 85-92. (doi:10.1016/ j.breast.2003.03.001)

Carstensen B, Witte DR \& Friis S 2012 Cancer occurrence in Danish diabetic patients: duration and insulin effects. Diabetologia 55 948-958. (doi:10.1007/s00125-0112381-4) 
Chan BT-Y \& Lee AV 2008 Insulin receptor substrates (IRSs) and breast tumorigenesis. Journal of Mammary Gland Biology \& Neoplasia 13 415-422. (doi:10.1007/ s10911-008-9101-9)

Chlebowski RT, Mc Tiernan A, Wactawski-Wende J, Manson JE, Aragaki A, Rohan TE, Kaklamani V, Vitolins M, Wallace R, Gunter M et al. 2012 Diabetes, metformin, and breast cancer in postmenopausal women. Journal of Clinical Oncology 30 2844-2862. (doi:10.1200/JCO.2011.39.7505)

Chodick G, Heymann AD, Rosenmann L, Green MS, Flash S, Porath A, Kokia E \& Shalev V 2010 Diabetes and risk of incident cancer: a large population-based cohort study in Israel. Cancer Causes \& Control 21 879-887. (doi:10.1007/s10552-010-9515-8)

Cleveland R, North K, Stevens J, Teitelbaum S, Neugut A \& Gammon MD 2012 The association of diabetes with breast cancer incidence and mortality in the Long Island Breast Cancer Study Project. Cancer Causes \& Control 23 1193-1203. (doi:10.1007/s10552-012-9989-7)

Colhoun HM \& Group SE 2009 Use of insulin glargine and cancer incidence in Scotland: a study from the Scottish Diabetes Research Network Epidemiology Group. Diabetologia 52 1755-1765. (doi:10.1007/s00125009-1453-1)

Coughlin SS, Calle EE, Teras LR, Petrelli J \& Thun MJ 2004 Diabetes mellitus as a predictor of cancer mortality in a large cohort of US adults. American Journal of Epidemiology 159 1160-1167. (doi:10.1093/aje/kwh161)

Currie CJ, Poole CD \& Gale EAM 2009 The influence of glucose-lowering therapies on cancer risk in type 2 diabetes. Diabetologia 52 1766-1777. (doi:10.1007/ s00125-009-1440-6)

De Waard F \& Baanders Van Halewijn EA 1974 A prospective study in general practice on breast cancer risk in postmenopausal women. International Journal of Cancer 14 153-160. (doi:10.1002/ijc.2910140203)

Ewertz M, Holmberg L, Tretli S, Pedersen BV \& Kristensen A 2001 Risk factors for male breast cancer - a case-control study from Scandinavia. Acta Oncologica 40 467-471. (doi:10.1080/028418601750288181)

Franceschi S, La Vecchia C, Negri E, Parazzini F \& Boyle P 1990 Breast cancer risk and history of selected medical conditions linked with female hormones. European Journal of Cancer 26 781-785. (doi:10.1016/02775379(90)90151-I)

Garmendia ML, Pereira A, Alvarado ME \& Atalah E 2007 Relation between insulin resistance and breast cancer among Chilean women. Annals of Epidemiology 17 403-409. (doi:10.1016/j.annepidem.2007.01.037)

Goodman M, Cologne J, Moriwaki H, Vaeth M \& Mabuchi K 1997 Risk factors for primary breast cancer in Japan: 8 -year follow-up of atomic bomb survivors. Preventive Medicine 26 144-153. (doi:10.1006/pmed.1996.9979)

Harvie M, Hooper L \& Howell AH 2003 Central obesity and breast cancer risk: a systematic review. Obesity Reviews 4 157-173. (doi:10.1046/j.1467-789X.2003.00108.x)
Hemminki K, Li X, Sundquist J \& Sundquist K 2010 Risk of cancer following hospitalization for type 2 diabetes. Oncologist 15 548-555. (doi:10.1634/theoncologist. 2009-0300)

Hjalgrim H, Frisch M, Ekbom A, Kyvik K, Melbye M \& Green A 1997 Cancer and diabetes - a follow up study of two population based cohorts of diabetic patients. Journal of Internal Medicine 241 471-475. (doi:10.1111/ j.1365-2796.1997.tb00004.x)

Home PD \& Lagarenne P 2009 Combined randomised controlled trial experience of malignancies in studies using insulin glargine. Diabetologia 52 2499-2506. (doi:10.1007/s00125-009-1530-5)

Hsieh MC, Lee TC, Cheng SM, Tu ST, Yen MH \& Tseng CH 2012 The influence of type 2 diabetes and glucoselowering therapies on cancer risk in the Taiwanese. Experimental Diabetes Research 2012413782. (doi:10.1155/2012/413782)

Inoue M, Iwasaki M, Otani T, Sasazuki S, Noda M \& Tsugane S 2006 Diabetes mellitus and the risk of cancer. Archives of Internal Medicine 166 1871-1877. (doi:10.1001/archinte.166.17.1871)

Jee SH, Kim HJ \& Lee J 2005 Obesity, insulin resistance and cancer risk. Yonsei Medical Journal 46 449-455. (doi:10.3349/ymj.2005.46.4.449)

Jiralerspong S, Palla SL, Giordano SH, Meric-Bernstam F, Liedtke C, Barnett CM, Hsu L, Hung M-C, Hortobagyi GN \& Gonzalez-Angulo AM 2009 Metformin and pathologic complete responses to neoadjuvant chemotherapy in diabetic patients with breast cancer. Journal of Clinical Oncology 27 3297-3302. (doi:10.1200/ JCO.2009.19.6410)

Jonasson JM, Ljung R, Talback M, Haglund B, Gudbjornsdottir S \& Steineck G 2009 Insulin glargine use and short-term incidence of malignancies - a populationbased follow-up study in Sweden. Diabetologia 52 1745-1754. (doi:10.1007/s00125-009-1444-2)

Jordan S, Lim L, Vilainerun D, Banks E, Sripaiboonkij N, Seubsman S, Sleigh A \& Bain C 2009 Breast Cancer in the Thai Cohort Study: an exploratory case-control analysis. Breast 18 299-303. (doi:10.1016/j.breast. 2009.09.004)

Kath R, Schiel R, Muller UA \& Hoffken K 2000 Malignancies in patients with insulin-treated diabetes mellitus. Journal of Cancer Research and Clinical Oncology 126 412-417. (doi:10.1007/s004320050038)

Key J, Hodgson S, Omar RZ, Jensen TK, Thompson SG, Boobis AR, Davies DS \& Elliott P 2006 Meta-analysis of studies of alcohol and breast cancer with consideration of the methodological issues. Cancer Causes \& Control 17 759-770. (doi:10.1007/s10552-006-0011-0)

Khachatryan L, Scharpf R \& Kagan S 2011 Influence of diabetes mellitus type 2 and prolonged estrogen exposure on risk of breast cancer among women in Armenia. Health Care for Women International 32 953-971. (doi:10.1080/ 07399332.2011.569041) 
Khan M, Mori M, Fujino Y, Shibata A, Sakauchi F, Washio M \& Tamakoshi A 2006 Site-specific cancer risk due to diabetes mellitus history: evidence from the Japan Collaborative Cohort (JACC) Study. Asian Pacific Journal of Cancer Prevention 7 253-259.

Khuder SA, Mutgi AB \& Nugent S 2001 Smoking and breast cancer: a meta-analysis. Reviews on Environmental Health 16 253-261. (doi:10.1515/ REVEH.2001.16.4.253)

Lambe M, Wigertz A, Garmo H, Walldius G, Jungner I \& Hammar N 2011 Impaired glucose metabolism and diabetes and the risk of breast, endometrial, and ovarian cancer. Cancer Causes \& Control 22 1163-1171. (doi:10.1007/s10552-011-9794-8)

Larsson SC, Mantzoros CS \& Wolk A 2007 Diabetes mellitus and risk of breast cancer: a meta-analysis. International Journal of Cancer 121 856-862. (doi:10.1002/ijc.22717)

La Vecchia C, Negri E, Franceschi S, D'avanzo B \& Boyle P 1994 A case-control study of diabetes mellitus and cancer risk. British Journal of Cancer 70 950-953. (doi:10.1038/ bjc.1994.427)

Lawlor DA, Smith GD \& Ebrahim S 2004 Hyperinsulinaemia and increased risk of breast cancer: findings from the British Women's Heart and Health Study. Cancer Causes \& Control 15 267-275. (doi:10.1023/B:CACO. 0000024225.14618.a8)

Lenfant-Pejovic M-H, Mlika-Cabanne N, Bouchardy C \& Auquier A 1990 Risk factors for male breast cancer: a Franco-Swiss case-control study. International Journal of Cancer 45 661-665. (doi:10.1002/ijc.2910450415)

Li CI, Daling JR, Tang MTC \& Malone KE 2011 Relationship between diabetes and risk of second primary contralateral breast cancer. Breast Cancer Research and Treatment 125 545-551. (doi:10.1007/s10549-010-1035-4)

Liao S, Li J, Wei W, Wang L, Zhang Y, Li J, Wang C \& Sun S 2011 Association between diabetes mellitus and breast cancer risk: a meta-analysis of the literature. Asian Pacific Journal of Cancer Prevention 12 1061-1065.

Lipscombe LL, Goodwin PJ, Zinman B, McLaughlin JR \& Hux JE 2006 Increased prevalence of prior breast cancer in women with newly diagnosed diabetes. Breast Cancer Research and Treatment 98 303-309. (doi:10.1007/ s10549-006-9166-3)

Martin-Castillo B, Vazquez-Martin A, Oliveras-Ferraros C \& Menendez JA 2010 Metformin and cancer: doses, mechanisms and the dandelion and hormetic phenomena. Cell Cycle 9 1057-1064. (doi:10.4161/cc.9.6.10994)

Michels KB, Solomon CG, Hu FB, Rosner BA, Hankinson SE, Colditz GA, Manson JE \& Nurses' Health Study 2003 Type 2 diabetes and subsequent incidence of breast cancer in the Nurses' Health Study. Diabetes Care 26 1752-1758. (doi:10.2337/diacare.26.6.1752)

Mink PJ, Shahar E, Rosamond WD, Alberg AJ \& Folsom AR 2002 Serum insulin and glucose levels and breast cancer incidence: the atherosclerosis risk in communities study. American Journal of Epidemiology 156 349-352. (doi:10.1093/aje/kwf050)
Moseson M, Koenig KL, Shore RE \& Pasternack BS 1993 The influence of medical conditions associated with hormones on the risk of breast cancer. International Journal of Epidemiology 22 1000-1009. (doi:10.1093/ ije/22.6.1000)

Mucha L, Stephenson J, Morandi N \& Dirani R 2006 Metaanalysis of disease risk associated with smoking, by gender and intensity of smoking. Gender Medicine 3 279-291. (doi:10.1016/S1550-8579(06)80216-0)

Muck BR, Trotnow S \& Hommel G 1975 Cancer of the breast, diabetes and pathological glucose tolerance. Archiv Für Gynäkologie 220 73-81. (doi:10.1007/ BF00673150)

Nestler J 2000 Obesity, insulin, sex steroids and ovulation. International Journal of Obesity 24 S71-S73. (doi:10.1038/sj.ijo.0801282)

Perrin MC, Terry MB, Kleinhaus K, Deutsch L, Yanetz R, Tiram E, Calderon-Margalit R, Friedlander Y, Paltiel O \& Harlap S 2008 Gestational diabetes and the risk of breast cancer among women in the Jerusalem perinatal study. Breast Cancer Research and Treatment 108 129-135. (doi:10.1007/s10549-007-9585-9)

Ragozzino M, Melton L, Chu C \& Palumbo P 1982 Subsequent cancer risk in the incidence cohort of Rochester, Minnesota, residents with diabetes mellitus. Journal of Chronic Diseases 35 13-19. (doi:10.1016/ 0021-9681(82)90025-X)

Resta F, Triggiani V, Sabba C, Licchelli B, Ghiyasaldin S, Liso A, Schittulli F, Quaranta M, Paradiso A, Tafaro E et al. 2004 The impact of body mass index and type 2 diabetes on breast cancer: current therapeutic measures of prevention. Current Drug Targets. Immune, Endocrine and Metabolic Disorders 4 327-333. (doi:10.2174/ 1568008043339686)

Rollison DE, Giuliano AR, Sellers TA, Laronga C, Sweeney C, Risendal B, Baumgartner KB, Byers T \& Slattery ML 2008 Population-based case-control study of diabetes and breast cancer risk in Hispanic and non-Hispanic White women living in US southwestern states. American Journal of Epidemiology 167 447-456. (doi:10.1093/aje/kwm322)

Ronco AL, De Stefani E, Deneo-Pellegrini H \& Quarneti A 2012 Diabetes, overweight and risk of postmenopausal breast cancer: a case-control study in Uruguay. Asian Pacific Journal of Cancer Prevention 13 139-146. (doi:10.7314/APJCP.2012.13.1.139)

Rosato V, Bosetti C, Talamini R, Levi F, Montella M, Giacosa A, Negri E \& La Vecchia C 2011 Metabolic syndrome and the risk of breast cancer in postmenopausal women. Annals of Oncology 112 630-634. (doi:10.1093/ annonc/mdr025)

Sanderson M, Peltz G, Perez A, Johnson M, Vernon SW, Fernandez ME \& Fadden MK 2010 Diabetes, physical activity and breast cancer among Hispanic women. Cancer Epidemiology 34 556-561. (doi:10.1016/j.canep. 2010.06.001) 
Sella T, Chodick G, Barchana M, Heymann AD, Porath A, Kokia E \& Shalev V 2011 Gestational diabetes and risk of incident primary cancer: a large historical cohort study in Israel. Cancer Causes \& Control 22 1513-1520. (doi:10.1007/s10552-011-9825-5)

Sellers TA, Jensen LE, Vierkant RA, Fredericksen ZS, Brandt KR, Giuliano AR, Pankratz VS, Cerhan JR \& Vachon CM 2007 Association of diabetes with mammographic breast density and breast cancer in the Minnesota breast cancer family study. Cancer Causes \& Control 18 505-515. (doi:10.1007/s10552-007-0128-9)

Shu X, Ji J, Li X, Sundquist J, Sundquist K \& Hemminki K 2010 Cancer risk among patients hospitalized for type 1 diabetes mellitus: a population-based cohort study in Sweden. Diabetic Medicine 27 791-797. (doi:10.1111/ j.1464-5491.2010.03011.x)

Siegelmann-Danieli N, Khandelwal V, Wood GC, Mainali R, Prichard J, Murphy TJ, Evans JF, Yumen O \& Bernath AM 2006 Breast cancer in elderly women: outcome as affected by age, tumor features, comorbidities, and treatment approach. Clinical Breast Cancer 7 59-66. (doi:10.3816/CBC.2006.n.014)

Sinagra D, Amato C, Scarpitta AM, Brigandi M, Amato M, Saura G, Latteri MA \& Caimi G 2002 Metabolic syndrome and breast cancer risk. European Review for Medical and Pharmacological Sciences 6 55-59.

Steenland K, Nowlin S \& Palu S 1995 Cancer incidence in the national health and nutrition survey 1 follow-up data: diabetes, cholesterol, pulse and physical activity. Cancer Epidemiology Biomarkers \& Prevention 4 807-811.

Stefansdottir G, Zoungas S, Chalmers J, Kengne AP, Knol MJ, Leufkens HGM, Patel A, Woodward M, Grobbee DE \& De Bruin ML 2011 Intensive glucose control and risk of cancer in patients with type 2 diabetes. Diabetologia 54 1608-1614. (doi:10.1007/s00125-011-2104-x)

Stroup DF, Berlin JA, Morton SC, Olkin I, Williamson GD, Rennie D, Moher D, Becker BJ, Sipe TA \& Thacker SB 2000 Meta-analysis of observational studies in epidemiology: a proposal for reporting. Meta-analysis Of Observational Studies in Epidemiology (MOOSE) group. Journal of the American Medical Association 283 2008-2012. (doi:10. 1001/jama.283.15.2008)

Swerdlow A, Laing S, Qiao Z, Slater S, Burden A, Botha J, Waugh N, Morris AD, Gatling W, Gale EA et al. 2005 Cancer incidence and mortality in patients with insulintreated diabetes: a UK cohort study. British Journal of Cancer 92 2070-2075. (doi:10.1038/sj.bjc.6602611)

Talamini R, Franceschi S, Favero A, Negri E, Parazzini F \& La Vecchia C 1997 Selected medical conditions and risk of breast cancer. British Journal of Cancer 75 1699-1703. (doi:10.1038/bjc.1997.289)
Thomas D, Jimenez L, Mc Tiernan A, Rosenblatt K, Stalsberg H, Stemhagen A, Thompson W, McCrea Curnen M, Satariano W, Austin D et al. 1992 Breast cancer in men: risk factors with hormonal implications. American Journal of Epidemiology 135 734-748.

Troisi R, Weiss HA, Hoover R, Potischman NA, Swanson C, Brogan D, Coates RJ, Gammon MD, Malone KE, Daling JR et al. 1998 Pregnancy characteristics and maternal risk of breast cancer. Epidemiology 9 641-647. (doi:10.1097/00001648-199811000-00014)

Tseng CH, Chong CK \& Tai TY 2009 Secular trend for mortality from breast cancer and the association between diabetes and breast cancer in Taiwan between 1995 and 2006. Diabetologia 52 240-246. (doi:10.1007/s00125008-1204-8)

Weiderpass E, Gridley G, Persson I, Nyren O, Ekbom A \& Adami HO 1997 Risk of endometrial and breast cancer in patients with diabetes mellitus. International Journal of Cancer 71 360-363. (doi:10.1002/(SICI)10970215(19970502)71:3<360::AID-IJC9>3.0.CO;2-W)

Weiss HA, Brinton LA, Potischman NA, Brogan D, Coates RJ, Gammon MD, Malone KE \& Schoenberg JB 1999 Breast cancer risk in young women and history of selected medical conditions. International Journal of Epidemiology 28 816-823. (doi:10.1093/ije/28.5.816)

Wideroff L, Gridley G, Mellemkjaer L, Chow W, Linet M, Keehn S, Borch-Johnsen K \& Olsen J 1997 Cancer incidence in a population-based cohort of patients hospitalized with diabetes mellitus in Denmark. Journal of the National Cancer Institute 89 1360-1365. (doi:10.1093/jnci/89.18.1360)

Wu AH, Yu MC, Tseng CC, Stanczyk FZ \& Pike MC 2007 Diabetes and risk of breast cancer in Asian-American women. Carcinogenesis 28 1561-1566. (doi:10.1093/ carcin/bgm081)

Yu ZG, Jia CX, Geng CZ, Tang JH, Zhang J \& Liu LY 2012 Risk factors related to female breast cancer in regions of Northeast China: a 1:3 matched case-control population-based study. Chinese Medical Journal 125 733-740.

Zendehel K, Nyren O, Ostenson C, Adami HO, Ekbom A \& Ye W 2003 Cancer incidence in patients with type 1 diabetes mellitus: a population-based cohort study in Sweden. Journal of the National Cancer Institute 95 1797-1800.

Received in final form 5 September 2012 Accepted 3 October 2012 Made available online as an Accepted Preprint 3 October 2012 